The Third Pole: Journal of Geography

Vol. 18 - 19: 111-122, 2019

DOI: https://doi.org/10.3126/ttp.v18i0.28012

Department of Geography Education,

Central Department of Education, T.U., Kathmandu, Nepal

\title{
ACADEMIC DISCOURSE ON THE DUALISM BETWEEN REGIONAL GEOGRAPHY AND SYSTEMATIC GEOGRAPHY
}

\author{
Kanhaiya Sapkota, $\mathbf{P h D}^{1}$
}

\begin{abstract}
This review based article entails that in the history of geography, one of the most exciting philosophical and methodological debates is the dualism between regional and systematic geography. This problem of "universality" and "exceptionality" has caused the biggest methodological debate in the history of geography. It reflects in the dualism of systematic geography and regional geography. Systematic geographers emphasize the pursuit of general principles in geography, while regional schools argue that areas of unique research are at the heart of geography. An analysis of the historical roots and evolution of the controversy shows that although the representatives of the two schools, Hartshorne and Schaefer, at least formally oppose the emphasis on only one of the systems and regions and neglect the other. Their differences in interest, values-induced preferences, and geography of history make them be ultimately different in their regional geography and systematic geography. The "SchaeferHartshorne Debate" in the 1980s was the only aftermath of this dualism. Since then, the rise of the pluralism methodology has made this dualism debate gradually fade out of people's horizons, but postmodern geography focuses on "critical regional research", which is still essentially a variant of this debate in the new era. The lack of such controversy in our geography community may be due to the academic orientation of "pragmatism". The academic environment, the academic evaluation system, and the theoretical construction of compromise. This is not conducive to Nepal's geography. It is independent of the world of science.
\end{abstract}

Key words: Regional geography; systematic geography; dualism; schaefer-hartshorne debate; pragmatism.

\section{Introduction}

As a comprehensive discipline, there are many dualisms in geography, such as nature and human, description and interpretation, science and art, systematic and regional,

1 Dr. Sapkota is an Associate Professor, Central Department of Geography, Tribhuvan University, Kathmandu Nepal, Email: kanhaiya.sapkota@gmail.com 
etc. (Martin, 2005). The studies in geography have always been conducted in either of the ways, viz. to study all the aspects in one region (chorological); or to study one aspect in detail throughout all the regions (systematic). The dualism in the general sense means to separate the two that should be unified or to emphasize only one of them and ignore the other. In many dualisms, is geography a "unique" discipline, or is it pursuing "universal" rules like other disciplines? This so-called "exceptional" and "universal" issue is actually a dualism that reflects the relationship between regional geography and systematic geography. It has caused the biggest debate in the history of geography. Before World War II, geography was not a discipline that was keen on the methodological debate. In the early stages after World War II, methodological debates in geography were still lacking compared to other disciplines such as economics.

Until Fred Schaefer published the article "The Exceptional Theory in Geography: A Review of Methodology" in 1953, provoked the "Quantitative Revolution" School (actually Systematic Geography) and the Regional School (Schaefer, 1953). The controversy lasted for more than 10 years, and by 1989 there was a special collection of papers summarizing the arguments of the two factions, showing the degree of influence (Entrikin \& Brunn, 1989). The greater significance of this controversy is that it has changed the static situation of the methodology of geography, and the first to open the atmosphere, making Western (human) geography more than 50 years the most enthusiastic subject of methodological discussion (Runchao, 2004). Therefore, for our academic circles, which are also relatively lacking in the discussion of methodologies, in-depth understanding and comprehensive reference to the rich achievements of foreign academic circles in methodology research is the only way to promote the discussion and research of the methodology of geography in Nepal (Koirala, 2010).

Therefore, this paper attempts to review and analyze the history of its evolution from a methodological perspective and explore its cause and effect. This article first traces the historical roots of this dualism debate, sums up its main points; and then focuses on the event that causes the debate to become more intense - "Schaefer-Hartshorne Debate" (it represents the arguments of the two schools), analyzes and discusses its causes; then prompts the aftermath of the debate, and finally summarizes and elucidates its significance.

\section{Materials and Methods}

This review article is based on the journal databases and published textbooks/reference books, i.e. internationally published papers mainly focused on the theme of geography, the dualism between regional and systematic concepts as well as other geographical 
ideas and knowledge. Therefore, the literature which I have reviewed were directly related to the topic which I have selected. In addition to that, I also have collected as much as available literature related to the various geographical discourses related to the Hartshorne - Schaefer debate. Thus, I believe that those renowned papers have accurate information and ideas. Finally, I believe that this paper will be useful for those people who have an interest in geographical thought and its development.

\section{Result and Discussion}

\section{Definition of systematic and regional geography}

The first to explicitly propose and define systematic geography and regional geography is the German geographer Bernhard Varenius. In 1650, he published Geographia Generalis, which was considered to be the first part of the issue of scholars who were keen on regional geography to ignore systematic geography and almost lost geography (Pedish, 1984). Regarding the relationship between regional and systematic geography, Varenius believes that geography is the part of hybrid mathematics that relies on quantity, i.e. shape, position, size, motion, and celestial phenomena to explain the state of the Earth and its parts. In addition to that, general geography is the general case of studying the whole earth and explains its various properties (Roller, 2015). It can be seen that Varenius not only officially defines regional geography and systematic geography but also emphasizes the application of quantitative methods in geography. He believes that general geography makes geography a "scientific" view consistent with Schafer's claim that geography should pursue universal law after 300 years, so Varenius seems to be a pre-modern period of geography. With regard to the division of general geography and specialized geography proposed by Varenius, how to evolve into systematic geography and regional geography, Richard Hartshorne has clearly stated:

"The terms general and special geography used by Varenius have become standard terms in these two aspects of European geography, although many authors are not satisfied with them in the future. German authors are describing general geography using the term Systematische (system) frequently, supporting the term Systematic geography in the country. Special geography, the term is largely replaced in the German literature by Landeskunde (regional geography), a word that has obvious flaws but is more commonly used than non-German specialized geography or is now widely used outside Germany and the phrase regional geography is more popular" (Hartshorne, 1959).

The estrangement of "Schaefer - Hartshorne debate". The dualism of regional and systematic geography has laid seeds in the historical period. However, with the continuous strengthening of the understanding of "unified" geography, the view that is 
extremely similar to Ptolemy's emphasis that negating another is gradually untenable. Therefore, most modern geographers are at least in the form. The above is a monist who advocates equal emphasis on the regional and the systematic. This is the first thing that should be paid attention to when analyzing the two school debates.

Although the regional school of thought emphasizes the regional research/approach as the core of geography. They also advocate that regional and systematic geography should be equal. For example, Hettner believes that the dualism of systematic and regional is a product of history. It is not enough to neglect any one of them. "Indicating chronological or historical, regional or spatial investigations should have a systematic or physical enquiry have the equal status" (Hettner, 1983). In addition to that, in his attitude towards systemic and regional dualism, Hartshorne is basically in agreement with Schafer. That is, they all agree with Hettner's critique of dualism and advocate both systematic geography and regional geography.

Whether it is the esteem of Hettner or its rigors and deep feelings, Hartshorne is strongly opposed to the dualism of systems and regions. For example, in the early work "The Nature of Geography", he summed up the differences between systematic geography and regional geography, but emphasized the relationship between the two, and proposed that "the two methods in the field of geography are promising. In a paper published in 1958, he pointed out that "like all other sciences which are concerned with the development and application of generic concepts and general principles or scientific laws, it is like history in that it is also concerned in large degree with the knowledge and understanding of individual, unique cases" (Hartshorne, 1958). In his 1959 monograph, he once again emphasized that the contrast between the terms 'systematic' or 'general' geography and 'regional' geography does not divide geography into two halves; nor is it a comparison of two significantly different research methods, one applied in some studies and the other in other studies. It is necessary to apply two different analytical methods to some extent and interactively in any geography study that the division of the unity place analysis and regional segmentation analysis (Hartshorne, 1959). Overall, Hartshorne is opposed to the dualism of systems and regions from beginning to end.

Similar to Hartshorne, Schafer also opposed regional and systematic dualism and attributed it to personal interests. He believes that regional and systemic disputes are similar to those of chickens and eggs. In fact, it is not necessary, because the laws established by systematic geography can be applied to regional geography. Simultaneously, regional geography can also provide specific material for systematic geography. In fact, it is juxtaposed, they interconnected but equal and independent discipline. At the same time, he also pointed out that one of the reasons for the dispute 
is the preference of geographers at different stages (Schaefer, 1953). These views and Hartshorne advocates basically the same that every scholar can be biased towards the type of research according to their own interests.

\section{Discourses on regional and systematic approaches in geography}

Although Hartshorne and Schafer both opposed the practice of emphasizing only one element in the systematic and the regional approach while ignoring the other. Their preferences or discourses led to a different inclination for the two in their final position. Even this tendency determines their methodological interests and positions.

Hartshorne's regional geography. Hartshorne strongly treats the regional geography as the foundation, core and ultimate goal of geography. For example, he not only cites Hettner's point of view, "only engaged in systematic geography work and does not cultivate regional geography, but such geographers also risk the complete departure from the geography base. People who do not understand regional geography not a true geographer". Thus, ultimately, geography is attributed to "the science of describing and interpreting the variability between the various parts of the Earth as a human world" (Hartshorne, 1959).

From this point of view, both Hettner and Hartshorne tend to regard regional geography as the core of geography. Although Hartshorne complained too many critics of the Nature of Geography and ignored his emphasis on systematic geography, his expression of the nature of geography, his narrative history of thoughts. The interest finally reflects that he still puts the "center of gravity" of geography on regional research. That is to say, although the formal rules and purpose requirements of the methodology make him reject the dualism, his personal interest and the weight of the historical view of thought are added to the regional geography, which in essence leads him to the geographical nature. The understanding is still focused on regional geography.

Schaefer's systematic geography. Schaefer draws on the examples of the development of natural science and economics and will seek the law of space. To do the ultimate goal of geography, we believe that "geography must pay attention to the spatial arrangement of regional phenomena, not the phenomenon itself; spatial relations are specialized fields of geographers, and non-spatial relations are specialized in other fields" (Schaefer, 1953). On this basis, Schaefer criticized the regional school's view that the regional geography application is regarded as the core of geography and that the application is also the implementation of the law, rather than the study of unique regions. 


\section{Differences between Hartshorne and Schafer's geography}

Hartshorne's view of geography history. Hartshorne's geography of history is concentrated in his 1958 documentary on the concept of geography. In this classic paper, Hartshorne traces the understanding of the concept of geography from Kant to Hettner, and divides this history into different stages. On the basis of different stages of the development, the views are basically consistent with general conclusions (Hartshorne, 1958). From this division, Hartshorne thinks that the evolution of the history of geography depends on the discipline itself and the modelling of geographers. He tries to find similarities between Kant, Humboldt, and Hettner. Therefore, Hartshorne's geography history view is "geography (home)" and seeks unity.

It seems that even in the case of Schafer's fierce criticism of his methodology, Hartshorne emphasis is still on the subjective nature of geography: the region, and more emphasis on the importance of this "discipline characteristics." From the 1939s to the $1959 \mathrm{~s}$, during the 20 years of Hartshorne's main content, his basic ideas on the methodology of geography have not changed much. This paper of 1958 may verify the correctness of Schafer's criticism from another level. In a sense, Schaefer's critique and some of the shortcomings of the intellectual history knowledge exposed in the process prompted Hartshorne to further strengthen his methodological beliefs.

Schaefer's view of geography history. Contrary to Hartshorne's first person who sees Kant as the concept of determining geography, Schaefer believes that Kant is the initiator of the exception theory. Schaefer believes that Kant-Hettner-Hartshorne is in the same vein and forms the historical chain of geography "exceptionalism". Hettner not only jumps out of Kant's circle but also coincided with Kant's geography and delighted that their authority and great prestige have made the "exceptional theory" deeply ingrained. This has caused geography to be "non-scientific andeven anti-scientific." Therefore, Schaefer's geography history view is "the (integral) science" standard, and it is considered that there is a major difference in geography history rather than a unified theme, which is completely contrary to Hartshorne's and regional schools. Now, Schaefer is clearly a staunch supporter of "scientism," and the actual history of geography has denied his extreme "scientism" arguments (such as humanistic geography).

Therefore, another main reason for this controversy lies in two different positions and perspectives on the history of geography: Schaefer's perspective is based on the current state of geography and other trends in scientific development and is critical to history while Hartshorne's perspective is based on the historical characteristics of the discipline. It is mainly affirmative of history and believes that the history of the 
discipline is basically unified. Inheriting this historical characteristic is to maintain the basic nature of geography, and that this is the direction of geographers' efforts. On the whole, it can be said that different values (personal interests, preferences and purposes) and historical views determine the difference in methodology.

The reverberation of the debate. The net outcome of Schaefer-Hartshorne Debate was that geography had come increasingly to be viewed as a science requiring the use of the scientific method' so that like other sciences, it could also develop laws and theories relevant to its field of study (Sapkota, 2018). This brought about a distinctive shift in emphasis from 'regional' to 'systematic' studies. This meant that geography thereafter began increasingly to be viewed in a nomothetic perspective. This also involved a shift from 'areal' to 'locational' studies; from 'absolute' to 'relative' locations; and from 'areal differentiation' to 'spatial interaction' (Sapkota, 2018).

With the rise of the "quantitative revolution" wave, the regional school gradually lost its momentum. However, the status of positivist geography emphasizes systematic ideas and methods which is not strong. Positivism geography has almost the same experience as the regional school of the 1960s. But it is worth noting that in the 1980s, there were some renewed calls for the revival of "regional geography" in the geography community. Representative of the American Association of Geographers, John Hart (1979) argued on his paper entitled "The Highest Form of Geographer Art", even caused him and the positivist debate on behalf of the president of the association. It is worth pondering that this argument is strikingly similar argument with Schaefer, but the impact is relatively small. It can be said that it is the aftermath of the regional and systematic dualism debate.

Unlike most other presidents' speeches, Hart's paper on this speech has caused much controversy. In this article, Hart reiterates the traditional view that geography focuses on the study area, and criticizes the "scientism" formed in the "quantitative revolution" (i.e. "narrowly believe that only the use of mathematical (quantitative) methods is correct, only in "scientific" advocacy), and "geography cannot lose its vitality in order to excessively pursue 'science'. Thus, systematic geography provides a general theory of regional studies, and regional geography validates this theoretical basis from reality. The regional thinking is the basic theme of the different branches of geography; the highest form of geographer art is to produce a vivid description that is easy to understand and evaluate... a geographer should respect the philosophical positions, values, and beliefs of other geographers and avoid Forcing others; geography and geographers should be more tolerant than coercive and have a portal" (Hart, 1982). 
Compared with the previous regional and systematic dualism debate, Hartshorne's article and its controversy have a much lesser influence. In fact, it may be only the aftermath of "Schaefer-Hartshorne debate", which is the regional and systematic dualism. The end of the argument, this kind of controversy may still exist, but more importantly, the argument that has not been fully developed and has stopped to some extent shows that both the debated parties and the audience seem to be suspicious of simple and repeated comparisons. Chicken and egg are important and controversial and feel tired. Nevertheless, the content of the debate and the debate itself project some valuable questions and propositions, such as the contradiction and tension between the subjectivity of the geographer and the "objective" of the research object. Thus, the history of geography is not purely "objective". "Historical facts themselves are subject to subjective elements such as personal understanding and preferences and so on. In geography, the reflection and discussion of the meaning, meaning and relationship of "subjective" and "objective" are not obsolete with the obsolescence of a theory.

Another reason for the gradual decline in the debate between regional and systematic dualism is the rise of pluralist methodology in geography. On the one hand, subject to the overall science (philosophy) from Thomas Kuhn's "paradigm" that turning to Paul Feyerabend's "Anything goes" methodology. The influence of geographers began to notice different geography thoughts due to differences in values, social systems, and ideologies. The choice of methodology is actually "political, personal, and accidental," so pluralism should be adopted to methodological position (Tickell, Sheppard, Peck, $\&$ Barnes, 2007). On the other hand, since the 1980s, geography has been influenced by postmodernism, "retreating from theoretical and general patterns, leading to the resurgence of regional research interests" (Richer, 1994), but the region is not a traditional region, nevertheless a "critical regional study" as described by Edward Soja (Soja, 2011) which is space, text, history, critical social theory, feminism, and many other local ideas, rather, "the system" thinking mean area under study. Therefore, this does not mean that regional geography has become the mainstream, but reflects the complex research situation of multi-dimensional convergence. In general, postmodern geography further emphasizes the fact that different epistemologies have their value, which not only breaks the binary opposition between the system and the region, makes it no longer the most compelling topic, but also promotes geography as going towards diversity doctrine. In general, postmodern geography further emphasizes the fact that different epistemologies have their value, which not only breaks the binary opposition between the system and the region, makes it no longer the most compelling topic, but also promotes geography towards pluralism. 
Regional vs systematic: Nepalese perspective. An important issue that needs reflection is the lack of discussion and debate on academic and methodological connections in the contemporary geographic study and research in Nepal. There are no geographers in Nepal to discuss the relationship between science and philosophy is in some sense related to regional and systematic dualism. Since the reform and opening up more than 20 years ago, the academic vision has gone far beyond the past, but the academic circles have been very indifferent to the debates on geography philosophy and methodology. Subedi (1993) introduced some of the epistemological debate on the positivistic and humanistic approaches in geography but could not address the debates on the importance of systematic and regional geography in Nepalese context. The reason may have been perceived by some geographers in Nepal and foreign scholars: the rationality of "pragmatism" makes them busy with applied or policy-oriented research, but lacks criticism of reality. In addition to that, the academic environment, the academic evaluation system, and the compromise of regional and systematic ideas by Nepalese geographers are also possible reasons.

Now a days, for the Nepalese geography, the geographers have been focusing on the dualism and debates on systematic and regional geography in the academia, rather than in their research papers. This debate reflects the importance of philosophical and methodological thinking and discussion for the development of disciplines. The abstraction of philosophical theory and down-to-earth work are always the two pillars of geography, which cannot be neglected. The lack of extensive, profound and thorough philosophical reflection on the development of disciplines is a shortcoming of Nepalese geography and one of the main reasons for the underdevelopment of our academic or university level geography knowledge. On the basis of a thorough understanding of the debates between western geography philosophy and methodology, the comparative study of the development of Nepalese geography, which concludes some generality and particularity, is the main path of our geography and relate research methodology. Indepth research and discussion on geography philosophy and methodology is a significant and urgent task for both the past and the current geography, and for the forward planning of future discipline development.

The geographical studies require the use of both types of approaches to area study. Because the systematic geography attempts to formulate the rules and laws, which may later be applied to regional studies. On the other hand, the regional geography serves as the basis for explanation. It also provides data for analysis to the systematic studies. Thus, it is appropriate to say that systematic and regional approaches are complementary to each other. They are inseparable and indispensable. In fact, one leads to the other and vice versa. 
Thus, the contrast expressed by the terms 'systematic' versus 'regional' is neither a division of geography into two halves, nor it is a contrast between two approaches. In fact, they both try to bring the extreme complexity of spatial interrelationships of phenomena into easily manageable form. It is necessary for any study in geography to use two different approaches in varying degrees and interchangeably. The laws of systematic geography or generalizations are unpredictable if they are not applied to regional or specific studies. Similarly, different areas or regions provide case studies to the general laws or theories. The actual purpose of systematic geography is to lead to an understanding of the causal relations of phenomena in areas, an understanding that may be expressed in principles that can be applied in the interpretation of individual regions, i.e. chorology.

Thus, both regional and systematic studies are included as essential parts of geography, and the question of their relative importance should be dismissed. For systematic geography, regional studies provide, not merely a source of detailed factual information that otherwise would hardly be available, but they also indicate problems of relationships that might easily be overlooked in systematic geography, and they provide the final testing ground for the generic concepts and principles of systematic geography. On the other hand, it is even more obvious that progress in the interpretation of the interrelated phenomena of regional geography is constantly dependent on the development of such universals by systematic studies. Any assumption that these studies can be left to the systematic sciences concerned with each particular category of phenomena has been shown by experience to be unwarranted.

\section{Conclusions}

In geography, the debate between "exceptional" and "universal" is actually a dualism of the historical root of regional and systemic geography. The big debate is the culmination of the intensification of the contradictions of Hartshorne and Schaefer debate. Although both of them oppose the practice of emphasizing only one element in the systematic and the region while ignoring the other. In particular, the two have different interests and value biases on regional and systematic approaches, and their history of geography is completely different. Based on the trend of overall scientific development, Schaefer is critical to history, regards the pursuit of the law as the core and purpose of science, and then regard geography as a science that pursues universal law as other disciplines; Hartshorne's loyalty to the historical characteristics of the discipline is the starting point for history. $\mathrm{He}$ believes that the historical feature of excavation and inheritance is to maintain the unity of geography and that this is the direction of geographers' efforts. Therefore, their foothold and starting point, preferences and historical perspectives caused by interests and values lead to different trends in regional geography and systematic geography, which leads to their final disagreement on geography and development orientation. 
The difference between values and historical views is not only an important part of the study of the methodology of geography but also the main driving force behind the evolution of Western geographical hegemony after World War II. After the 1950s, the theory of "georevolution" in Western geography was frequent, and the tides and overlap of positivism, structuralism, humanism, and post-modernism. The root cause of these dramatic changes is that traditional geographers focus on "what is geography?", and the post-World War II geographers are more concerned about "what geography should be?" (Johnston \& Sidaway, 2015). The word "should" indicates the importance of value judgment to modern and contemporary geography. In fact, by analyzing the history of the evolution of regional and systematic dualism, it can be found that the definition of geography nature and focus by traditional geographers is also influenced by its preferences and values, and its understanding is also a product of specific historical conditions. The change of values has made more realistic demands on geographers with the rapid changes of the times and society, and it has made geography more oriented towards reality and the future, rather than immersing and staying in tradition. From a historical perspective, especially from the whole process of regional and systematic dualism debates, this is even more obvious: any classic will become a tradition, and this tradition is even a sign that distinguishes one discipline from other disciplines, but it also faces descendants. Forgotten fate. An excellent tradition may be restored at some point in time, but it will never appear in the appetite of latecomers. Any traditional revival contains the proposition of the times and is carried out under its stimulation and constraints. Therefore, when the methodological discussion of regional and systematic dualism is freed from the shallower and shallower level, and the deeper level of the debate on the values and historical views of the debate, this old topic will have a new interpretation.

\section{References}

Abler, R. F. (1987). What shall we say ? To whom shall we speak ?. Annals of the Association of American Geographers, 77(4), 511-524.

Entrikin, J. N., \& Brunn, S. D. (1989). Reflections on Richard Hartshorne's The nature of geography. Washington D. C.: The Association of American Geographers.

Golledge, R. G., Church, R., Dozier, J., Estes, J. E., Michaelsen, J., Sirnonett, D. S., . . . Tobler, W. R. (1982). Commentary on The highest form of the geographer's art. Annals of the Association of Americian Geographers, 72(4), 557-558.

Hart, J. F. (1982). Comment in reply. Annals of the Association of American Geographers, 72(4), 559.

Hart, J. F. (1982). The highest form of the geographer's art. Annals of the Association of American Geographers, 72(1), 1-6.

Hartshorne, R. (1958). The concept of geography as a science of space, from Kant and Humboldt to Hettner. Annals of the Association of American Geographers, 48(2), 97-108. 
Hartshorne, R. (1959). Perspective on the nature of geography. Chicago: The Association of American Geographers.

Hartshorne, R. (1996). The nature of geography: a critical survey of current thought in the light of the past. USA: Association of American geographers.

Healey, R. (1983). Regional geography in the computer age: A further comment on the highest form of the geographer's art. Annals of the Association of American Geographers, 73(3), 439-441.

Hettner, A. (1983). Geography: The history, nature, and methods of it. London: The Commercial Press.

Johnston, R. (2003). Order in space: Geography as a discipline in distance. In W. M. Johnston R, A century of British geography (p. 331). Oxford: Oxford University Press.

Johnston, R., \& Claval, P. (2013). Geography since the second world war: An international survey. (R. Johnston, \& P. Claval, Eds.) London and New York: Routledge.

Johnston, R., \& Sidaway, J. (2015). Geography and geographers: Anglo-American human geography since 1945 (7th ed.). New York and London: Routledge.

Koirala, H. 1. (2008). Geography in crisis: Is geography in Nepal an exception? The Geographical Journal of Nepal, 6, 31-44.

Koirala, H. L. (2010). Are geographer's research methodologies really poor? Tribhuvan University Journal, 27, 61-70.

Lewis, P. (1985). Beyond description. Annals of the Association of American Geographers, 75(4), 465-478.

Martin, G. J. (2005). All possible worlds: History of geography thoughts (4th Edition ed.). London: Oxford University Press.

Pedish, P. (1984). The geography of anciet Greeks: The history of ancient Greek geography. Paris: The Commercial Press.

Richer, J. (1994). Sacred geography of the ancient Greeks: Astrological symbolism in art, architecture and landscape. New York: State University of New York.

Roller, D. W. (2015). Ancient geography: The discovery of the world in classical Greece and Rome. Tauris: I B Tauris.

Runchao, M. (2004). The evolution of western economic geography and the understanding of geoscientists across the Taiwan Straits. Geography Research, 23(5), 574.

Sapkota, K. (2018). Fundamentals of geographical thought. Kathmandu: Mahila Ojashwi Manch.

Schaefer, F. K. (1953). Exceptionalism in geography : A methodological examination. Annals of the Association of American Geographers, 43(3), 226-249.

Soja, E. (2011). Postmodern geographies: The reassertion of space in critical social theory. London, New York: Verso.

Tickell, A., Sheppard, E., Peck, J. A., \& Barnes, T. (2007). Politics and practice in economic geography. London; New York: SAGE Publication. 